\title{
A FILHA DO PIANISTA
}

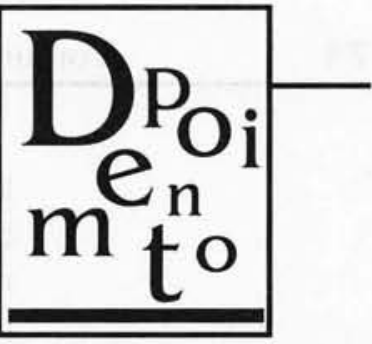

\section{Contar histórias e fazer rir são as atividades preferidas da atriz que faz ponte entre $o$ teatro e a televisão}

\section{$1^{\circ}$ ATO}

Vamos nascer logo, passar a infância correndo, depois estudar rápido, ir para o teatro divertir logo, ter filho, casar, ganhar uns prêmios. Vamos logo para voltar rápido. Depois eu morro, vocês choram rápido: velório de meia hora, enterra logo e eu volto para a minha terra. Vocês aqui fazem um museuzinho com minhas roupas velhas, e assim tá feito.

Depoimento: Nasci, vivi, tive filho, namorei bastante, casei com dois homens surpreendentes - um pior do que o outro - fiz teatro, cantei, chorei, gostei, morri, pano rápido, adeus.

Nasci sobre folhas de jornais, tal a pressa com que eu quis vir ao mundo.

Por causa disso, minha Mãe dizia que eu seria jornalista, mas na sala de casa, silencioso, meu pai tocava piano e, no quintal de casa, eu fazia teatrinho para as minhas irmãs, coberta com os panos de minha Mãe e embalada pelo piano de meu Pai.

Dos 13 aos 19 anos eu era o próprio silêncio, como uma ostra no fundo do mar, guardava uma pérola cheia de personagens, as quais uma cabeça jovem pode transportar por todas as ruas e ninguém descobrir o que ali estava sendo sonhado. Estudava no Rainha da Paz e era apaixonada pelo motorista do ônibus escolar, momentos de amor.

Estudei Jornalismo na ECA, e fazia teatro com os alunos, o Gteca. Minha primeira peça chamava-se "A Invasão dos Porcos", era sobre a invasão da polícia na Universidade, mas como vivíamos sob a ditadura, tínhamos que chamá-la de "A Resistência".

Freqüentava as reuniões da Divergência Socialista (sic) mas, por falta de consciência política, não pude mais freqüentar as reuniões sem entender direito a diretriz política daque- 
le momento, em que uma menina de 19 anos teria que ter "consistência”. Afinal de contas eu não era um bolo, uma massa para ser manobrada pelos colegas. Esqueciam que o fermento é jogado no caminho da vida.

\section{$2^{\circ}$ ATO}

Fui trabalhar e meu primeiro emprego foi de tradutora de telegramas, no Correio, junto com a atriz Eliane Giardini. O trem saía do Alto da Lapa e lá ia eu, às seis da manhã, trabalhar nas loucuras das traduções. Sonhava viajar, enquanto passava o dia sentada escrevendo para o mundo. Imaginava o outro lado recebendo as notícias, quando, muitas vezes, pensava serem minhas aquelas palavras: -"Amor, volto logo, muito trabalho".

-"Brasil é lindo, mas falta dinheiro".

-"Negócios estão emperrados, falta acertar 6\% de propina de Monsieur Netto".

-"Aqui nada funciona, se não voltar logo, morro de angústia".

Assim passávamos os dias traduzindo o sofrimento do mundo, sentadas no rumo das pessoas que aqui sofriam.

Carlos Alberto Sofredini precisava de uma atriz que cantasse. Douglas Salgado comprometeu-se a procurar a atriz Roseli Silva e levá-la ao teatro para um teste, mas como nós duas temos um nariz muito parecido, eu é quem fui levada para fazer o teste. Toda hora alguém me chamava de Roseli e à noite, quando chegou a verdadeira Roseli, ninguém teve coragem de me mandar embora, afinal meu nariz era maior e eu também cantava.

A primeira peça, Don Quixote de la Mancha, por ter cenas de circo, era considerada alienada, e alguns anos depois eu faria Mãe Ubu, no Ornitorrinco, toda em circo, o teatro ficava lotado todas as noites para ver o circo pegar fogo.

Depois fizemos a peça A Farsa de Inês Pereira. Nesta época, não esperávamos patrocínio para fazer teatro, fazíamos.

Todos os atores ajudavam na criação de cenários, figurinos, adereços. "Carpintaria" é o termo exato. Nós entrávamos no teatro e só saíamos de madrugada, no outro dia a mesma coisa, até terminar e poder apresentar a peça. Antes, porém, tínhamos que chamar 0 "censor" da polícia federal para fazer a censura.

Era uma época extremamente ridícula, ditadura, militares, comunistas, "libelu", "divergência"... A repressão funcionava dos dois lados e existia a patrulha ideológica, tão ridícula quanto os milicos. 


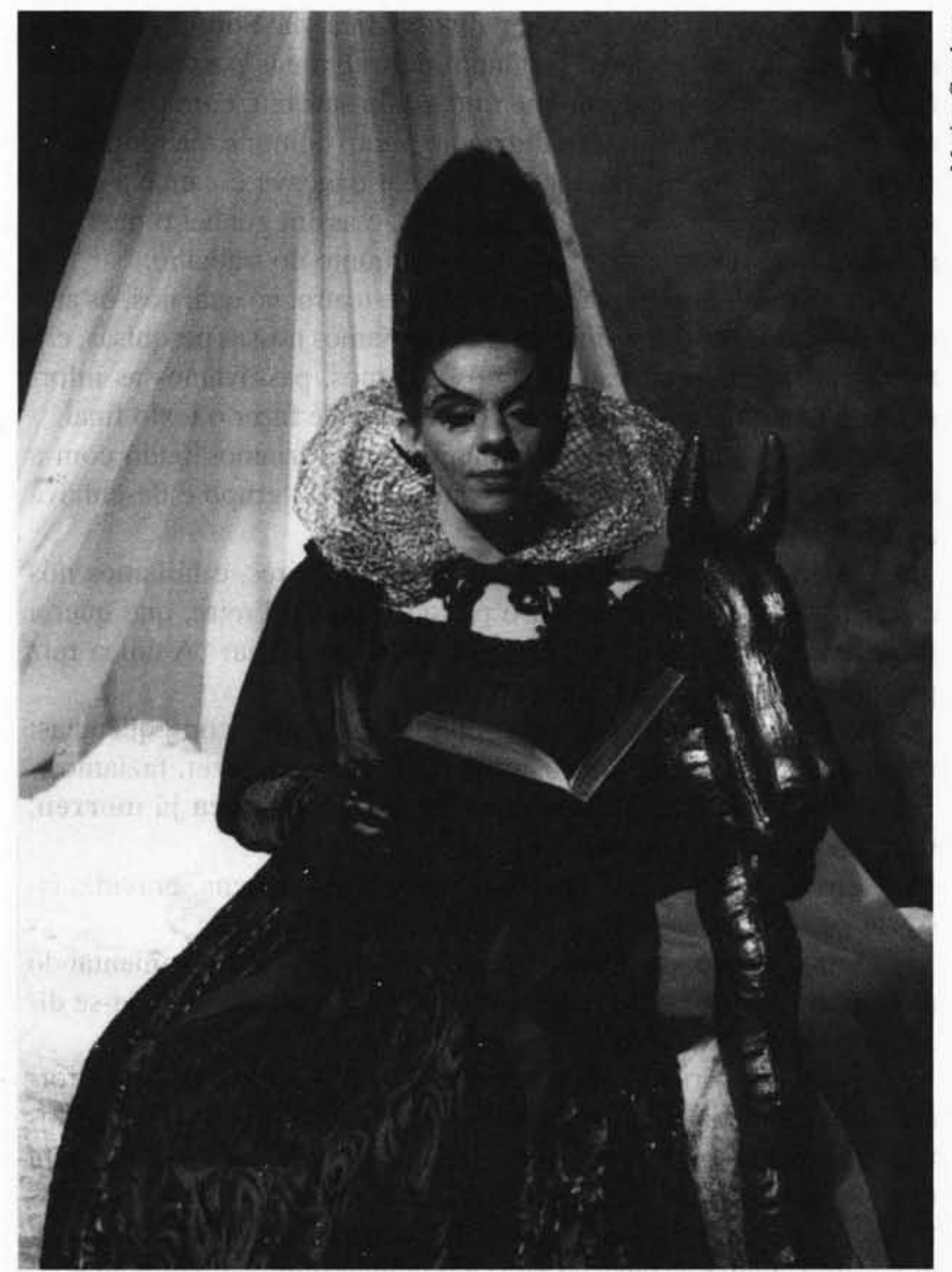

A bruxa Morgana, interpretada por Rosi Campos, no Castelo Rá-Tim-Bum, encanta a criançada com suas histórias.

\section{$3^{\circ}$ ATO}

Uma teia de barbante, botinas sujas, vestidos velhos, três atores em cena: eu, Calixto de Inhamuns e Maria do Carmo Soares, dirigidos por Vignatti.

Minha Mãe chorava na platéia por ver-me tão mal vestida, quantos vestidos na juventude? Ali a filhinha tão pobrezinha, querendo matar os pais. 
Formada, fui trabalhar de divulgadora da Som Livre para manter-me fazendo teatro, juntando mais algumas pessoas, em 79, fizemos a peça Vem buscar-me que ainda sou teu, com pesquisa e texto de Carlos Alberto Sofredini, com muito humor e talento, imensos painéis coloridos, muitas bolotas. Eu dançava e cantava como uma argentina mui famosa em meu país, e assim ganhei o meu primeiro prêmio de atriz revelação pelo conjunto do trabalho.

No Mambembe, eu aprendi a fazer o teatro, no qual nós, os atores, orientados por Sofredini e Calixto, fazíamos nossas pesquisas, entrevistávamos pessoas, estudávamos e líamos, passávamos as informações ao autor Luís Alberto de Abreu para ele fazer o texto final.

Arranjávamos empréstimos em banco; fazíamos fiado com a costureira, o figurinista, Irineu Chamiso, era do grupo e desenhava e pintava os painéis.

Muitas vezes ensaiávamos em Ribeirão Pires, e lá íamos nós de trem. Conversávamos com o pai de Ednaldo Freire, que queria saber que tipo de teatro popular fazíamos, ele dizia: "A única raiz popular que eu conheço é a raiz de mandioca".

Enfim, levávamos nossos sonhos às últimas conseqüências: não tinha boiada muito menos moleza, se era para fazer, fazíamos.

Assim nasceu: Foi bom meu bem?, Cala a boca já morreu, Círculo de Cristal e Bella Ciao.

Em Cala a boca já morreu, eu entrava em cena, grávida, isso até os seis meses.

Em Círculo de Cristal, comecei os ensaios amamentando meu filho Pedro Brandi, então com seis meses, de quem pode-se dizer que foi gerado e criado no teatro.

Parece história de circo, mas é a vida. O Teatro é livre das formalidades de uma empresa convencional. $\mathrm{O}$ que importa o sexo dos anjos? Precisamos é viver nossos sonhos, não importando a hora que temos que vivê-los; aliás, não temos horário e nem precisamos ficar em casa esperando um convite de trabalho como uma donzela, precisamos juntar as boas pessoas e trabalhar muito, em qualquer situação econômica ou política.

Foi assim que eu vivi, vivo e aprendi.

A única vaidade permitida a uma pessoa de teatro é o próprio teatro. É a cena bem feita, a história bem contada, as pessoas na platéia sorrindo ou chorando, vivendo seus sonhos nos nossos atos, esquecendo a vida complicada lá fora.

Apagam-se as luzes e acendem-se as fantasias. Não para que eu seja vista por 400 ou 30 pessoas, mas para que estas pessoas possam viver a nossa loucura, isto é, a arte de representar. 


\section{$4^{\circ}$ ATO}

O Mambembe fez Besame Mucho, de Mário Prata, e uma parte do elenco fundou o Arte Viva, sob orientação de Calixto de Inhamuns, e criou o Bella Ciao, com texto de Alberto de Abreu (Zé de Abreu).

Recebi um convite de Cacá Rosset, indicada por Chiquinho Brandão, o ator completo (ator - cantor - músico), um gênio na criação, na improvisação, suas histórias são simplesmente hilariantes. Um dos melhores atores com quem contracenei. Falta em São Paulo um "Teatro Chiquinho Brandão". Levei comigo ao Ornitorrinco a atriz Cristiane Tricerri e fizemos Pai Ubu, com direção de Cacá Rosset.

Ganhei vários prêmios de melhor atriz, trememos o México em 85, acordamos o vulcão na Colômbia e derrubamos o Muro de Berlim.

Cacá Rosset é um diretor que respeita a criação do ator, dá plena liberdade e, quando a idéia é boa, coloca em cena sem ter a mesquinha preocupação de ser ele o único diretor, é um trabalho de equipe. Ele não tem a infantil preocupação de mudar o andar ou a voz dos atores. Ele sabe que ator e atriz representam com a emoção e a inteligência.

No Ornitorrinco, os atores sabem que vão trabalhar e ganhar dinheiro por dois ou três anos, Cacá não tem a frustração de ator-diretor, que quer sempre matar as peças de que participa. Fizemos Teledeum, censurada em plena abertura democrática, mas foi tão grande o movimento da classe teatral, acostumada com os anos de ditadura, que liberamos Teledeum.

Mas um dia a gente descobre que pode ter o próprio grupo de teatro e não ficar só fazendo peças de diretores, sem saber quanto de dinheiro entrou na bilheteria. Eu queria fazer a minha "lojinha".

Queria fazer o que quisesse ou gostasse, minha satisfação ainda é o tempo do Mambembe, quando nós pesquisávamos, líamos, estudávamos e um autor fazia o texto da maneira que nos agradasse.

Sentia falta de mandar no meu nariz, grande por sinal, mas também é a minha sina.

Sonhar, sofrer, apanhar, aprender, descobrir o quero. Não queria encomenda pronta, pode não ser a melhor coisa do mundo, mas é o que eu sempre quis e posso dizer que eu ainda não fiz o que eu quero no teatro. Percebo que a cada dia tenho mais coisas para 
aprender e mais teatro para fazer. Nunca estou satisfeita, os prêmios todos deixaram-me emocionada e feliz, com lágrimas agradeci aos aplausos, mas a noite vem e em minha casa, com minha família, a ansiedade vem forte e estudando vejo que ainda há muita coisa para ser feita.

$\mathrm{Na}$ verdade, quando chegamos a uma certa idade, percebemos que tudo na vida é feito de lutas, de aprendizado. O aparente ou verdadeiro sucesso é muito bom, mas não é isto que norteia minha vida. Gosto mesmo é do trabalho em conjunto, gosto de ver as coisas sendo feitas, as cenas surgindo em cada cabeça, as pessoas satisfeitas por estarem trabalhando. Não tive e nem tenho a necessidade de existir só com um sucesso, pois eu tenho consciência de que ele é construído por muitas pessoas, assim é o teatro, sempre foi, e sempre será, e quem não seguir seu rumo traçado no plano espiritual, um dia vai perceber que a escuridão do teatro é verdadeira.

Se não existir o maquinista, a cortina não se vai levantar; se não existir a costureira, os figurinos vão desmanchar; se não existir o carpinteiro, o cenário não vai existir.

Cada pessoa constrói o seu mundo, e depois tem que habitá-lo.

\section{$5^{\circ}$ ATO}

Em 1989, resolvi ter meu próprio grupo, assim nasceu o Circo Grafitti. A proposta era fazer o que eu queria ou gostasse, sem ter que buscar texto que fosse sucesso em Nova York.

Muitas idéias eu tinha na cabeça, sem saber por onde começar, juntei-me com Helen Helene e partimos para a luta.

Em São José do Rio Preto, perguntei a um jovem diretor que tinha ganho vários prêmios: "O que se vai fazer com tudo isso?" Ele respondeu no ato: "É para te dirigir..." E um dia bateu na minha porta, querendo trabalhar comigo, aí começamos a desenvolver várias idéias.

Mas o destino, às vezes, parece querer a volta de nossas origens, assim um dia Luciano Lopreto, professor da Aliança Francesa, apresentou-nos o livro de Raymond Queneau, Exercícios de Estilo.

Helen, que também entende o francês, caiu na risada, e assim nós duas morremos de rir com Queneau. Gabriel Villela percebeu que ali estava o texto que estávamos procurando, surgiu assim, a peça Você vai ver o que você vai ver, como se fosse num circo. 
Gabriel teve a idéia de fazer a peça num ônibus. Por mais de dois meses freqüentou a extinta CMTC (Companhia Municipal de Transpostes Coletivos), orientando os técnicos como seria o tal ônibus enquanto eu e Helen Helene ficávamos noites inteiras, na cozinha de minha casa, traduzindo e inventando as cenas. Pedro Paulo Bogossian criou as músicas, ensaiamos clown e estreamos no Centro Cultural São Paulo, no foyer, com muito sucesso. Ganhamos ao todo 17 prêmios no Brasil e exterior. Jean Claude Carrière, roteirista de Buñuel e Peter Brook, disse que a nossa montagem era a mais bonita que tinha visto.

Depois de muita pesquisa, surgiu Noemi Marinho com a peça Almanaque Brasil, como não tínhamos muito tempo para estrear, tudo foi feito em pouco mais de 30 dias, assim entramos no Teatro Ruth Escobar, para o início de mais um sucesso do Circo Grafitti.

Seguindo a trajetória de fazer comédia-musical, descobri na Casa de Dante um texto do século XI, dos goliardos, daí surgiu Ifigônia, com direção de Roney Fachini, adaptação de Mário Vianna e tradução de Bri Fiocca.

Antes eu fiz Avenidas do mar aberto, com direção de Sérgio Ferrara.

Ifigônia me fez voltar ao clima de 68 , fomos impedidos de apresentar a peça no Centro Cultural São Paulo, isto é, fomos censurados.

A incoerência das pessoas assusta-me, mas como meu destino é fazer, eu faço enquanto elas ficam paradas sem saber o rumo da vida. A mim não cabe ter vergonha de meus atos, porque acima de qualquer coisa na vida eu preservo a liberdade de expressão como uma verdade fundamental, mesmo que esta verdade venha, por alguma razão, incomodar-me.

Não aceito uma lei para mim e outra para os outros, quero ter os mesmos direitos, assim como tenho minhas obrigações.

Se eu lutei e denunciei a censura em 79, faço-o novamente em 96, e assim farei enquanto estiver lutando para viver com meu trabalho.

Quem somos nós para censurar uma peça de teatro?

Liberdade é um direito do trabalhador, mesmo que ele seja encanador ou ator.(Aliás, é na terra de Sartre que uma atriz é esfaqueada). Ninguém pode desprezar o trabalho de uma pessoa. O lixeiro pega as sobras mais limpas de nossa sociedade, trabalhasse ele no Congresso ou na Assembléia, aí sim ele veria o verdadeiro lixo que existe no Brasil. 


\section{$6^{\circ}$ ATO}

Há muitos anos vivo de teatro, locuções e comerciais. Fiz na TV Cultura a querida personagem Morgana e a cada dia era uma maneira de contar ao meu filho as histórias da humanidade, divertia-me divertindo as crianças. Em qualquer país mais inteligente o Castelo ainda estaria no ar com novos capítulos, novas idéias, gerando trabalho a muita gente criativa de São Paulo.

Com muito profissionalismo e respeito, Wolf Maia convidoume a trabalhar na novela Cara e Coroa. Dirige as cenas com tranqüilidade e segurança e gosta de inventá-las. Muitas pessoas me perguntam sobre o clima na Globo, respondo que o ar condicionado funciona muito bem. Ninguém tem tempo para frescura, todos os atores, com mais experiência do que eu, sempre me deram toques de como posicionar-me perante a câmera, sobre como ocupar o espaço no vídeo. Cristiane Torloni, sempre atenta, orientou-me muitas vezes sobre como fazer minha personagem crescer, como agir na movimentação. Cada um constrói o mundo à sua maneira, e assim estou gostando muito de trabalhar com profissionais talentosos e conscientes de sua responsabilidade perante quase 40 milhões de pessoas. Assusta um pouco, quando, ao caminhar na rua, as pessoas olham para você e gritam o nome da personagem, dá timidez e dá prazer. No teatro, o ator é desconhecido do grande público, na Globo você começa a fazer parte da vida das pessoas, e com isto a intimidade torna-se muito grande. Mas bom mesmo é ouvir as histórias de grandes atores como Hugo Carvana, Carlos Zara, Toni Tornado, ele me vendeu um lindo carro Peugeot 95, com vidro elétrico e ar condicionado.

Na Globo sinto-me em São Paulo, no SBT - quando fiz Brasileiros e Brasileiras - sentia-me no Rio de Janeiro. Vi no SBT como é fácil, alguém de poder, destruir uma novela, enganar as pessoas, enganar a quem paga seu salário.

Hoje, posso dizer tranqüila que aprendi muito sobre profissionalismo, competência e, principalmente, respeito a uma atriz que faz teatro. Dentro da Globo, eles respeitam o fato de você fazer novela e fazer teatro.

Alguns diretores de telenovela querem que você deixe o teatro para fazer novela e isto não é correto.

$O$ ator de teatro precisa do teatro, assim como o teatro precisa do ator. São movimentos naturais, o teatro cresce na medida em que crescemos, trabalhamos, criamos, inventamos. A televisão entra na sua casa, no teatro o público entra na nossa casa. 
São maneiras distintas de trabalhar. Você aprende tanto em um quanto em outro, mas é no teatro que o ator recebe a resposta imediata, é sem frescura a troca de sonhos ou frustrações, seja como você preferir. Eu, particularmente, prefiro a minha parte em dinheiro.

\section{$7^{\circ}$ ATO}

No teatro escuro, eu caminho em direção ao camarim, as luzes em volta do espelho vão realçar as marcas no rosto, mas com pó de arroz e batom eu pinto a minha cara de palhaça, retoco os olhos, visto a minha farda de atriz que não é nenhum fardo. Olho através do espelho, de qualquer bancada, porque eu nunca tive meu "altar" no camarim, gosto de ver a movimentação das pessoas. Cada dia uma história, cada dia um silêncio, uma armação para delírio dos loucos.

Quando abre a cortina, vai dormir a menina que um dia sonhou em ser fonoaudióloga, acorda a comediante, que muitas vezes se diverte no palco mais que a platéia e, quando perguntam por que não faço tragédia?, respondo: "Já basta a vida". Acende a luz no palco, eu procuro no fundo escuro do teatro o pianista que tocou todas as músicas de minha infância, solitário dentro de casa, dava mais vida a nossas vidas, tocando piano perguntava-me: "Onde vai você, João Ratão, com tanta pressa?" 